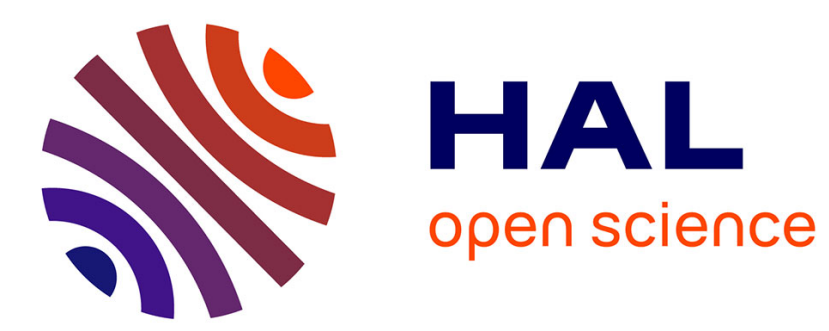

\title{
DEVELOPMENT OF AN STM-LEED-FIM COMBINATION SYSTEM
}

\author{
G. Xiao, Hong Liu, S. Chi, Z. Xue, Xiaojian Li, T. Tsong
}

\section{To cite this version:}

G. Xiao, Hong Liu, S. Chi, Z. Xue, Xiaojian Li, et al.. DEVELOPMENT OF AN STM-LEEDFIM COMBINATION SYSTEM. Journal de Physique Colloques, 1988, 49 (C6), pp.C6-37-C6-42. 10.1051/jphyscol:1988607 . jpa-00228104

\section{HAL Id: jpa-00228104 https://hal.science/jpa-00228104}

Submitted on 1 Jan 1988

HAL is a multi-disciplinary open access archive for the deposit and dissemination of scientific research documents, whether they are published or not. The documents may come from teaching and research institutions in France or abroad, or from public or private research centers.
L'archive ouverte pluridisciplinaire HAL, est destinée au dépôt et à la diffusion de documents scientifiques de niveau recherche, publiés ou non, émanant des établissements d'enseignement et de recherche français ou étrangers, des laboratoires publics ou privés. 
JOURNAL DE PHYSIQUE

Colloque $C 6$, supplément au $n^{\circ} 11$, Tome 49, novembre 1988

DEVELOPMENT OF AN STM-LEED-FIM COMBINATION SYSTEM

\author{
G.L. XIAO, H.F. LIU, S.D. CHI, Z.Q. XUE, X. II and T.T. TSONG \\ Physics Department, The Pennsylvania State University, University \\ Park, Pennsylvania, PA 16802, U.S.A.
}

\begin{abstract}
This is a progress report of an STM-LEED-FIM combination system we have been developing over the last one and a half years. The basic idea is to build an STM having its tip characterized and manipulated in the FIM mode, and also having its sample examined by low energy electron diffraction. At the present time, each individual system is in good operating conditions, but the STM is not yet instałled into the vacuum system. We present here preliminary data of LEED on the (7×7) reconstructed $S i$ (111) surface, and some STM images of surfaces of graphite, gold foil, gold crystal and platinum sheet with the STM operated in atmosphere. Atomic structures and atomic steps of the graphite (111) surfaces, larger structures of the metal surfaces, and columnar and particulate structures of $r f$ sputtered thin Au films can be observed. The dynamical behavior of these surfaces at room temperature are also clearly seen.
\end{abstract}

\title{
I. INTRODUCTION
}

This is a progress report of an STM-LEED-FIM combination system we have been developing over the last one and a half years. Although STM is a powerful technique for imaging the three-dimensional topography of solid surfaces with a vertical resolution of better than $0.1 \AA$ and a lateral resolution as good as $-3 \AA,{ }^{1}$ reproducible results are difficult to obtain. One of the reasons is that the atomic structure of the scanning tip is changing continuously during the STM scan. One would also like to manipulate and characterize the STM tip before it is used for imaging, and characterize the tip again after it is used for the imaging, so that not only the STM result can be reproducible, but also proper interpretations of the STM result can be done. To achieve the best resolution of the STM, one would like to have a single atom-tip. Characterization and manipulation of STM tips can be done in the field ion microscope, as has been reported by Kuk and Silverman, ${ }^{2}$ and also by others.

We would also like to be able to characterize STM samples with low energy electron diffraction. STM provides the atomic structures of surfaces of microscopic sizes. When a tip is scanning a sample, in reality, the sample is also scanning the tip. If the dimension of the atomic structure of the sample surface being scanned is comparable to that of the tip surface doing the scanning, then STM images will give the interference pattern of the two atomic structures, not really the atomic structure of the sample surface. Thus it is not always easy to interpret STM images properly. LEED will be able to provide the dimension and symmetry of the surface net of the sample, and therefore can 
facilitate greatly the analysis of STM data. LEED itself is of course one of the most powerful techniques for studying the atomic structure of solid surfaces. Unfortunately, the spot size covers too large an area within which there may be more than one atomic structure. For example, we find that when a silicon sample is annealed at $800{ }^{\circ} \mathrm{C}$ in $\mathrm{UHV}$, two completely different atomic structures of the reconstructed surface are formed on the (023) plane. $^{3}$ Similar results have also been obtained for other crystal surfaces with the STM. The STM, on the other hand, can provide this information by scanning at the different spots of a surface. Thus by combining LEED, STM and FIM, we hope to develop a truly versatile instrument for studying the atomic structure of solid surfaces, and also atomic processes occurring on solid surfaces.

\section{INSTRUMENT DESIGN}

The system consists of a commercial reversed view LEED optics, model RVL 8-120, of Princeton Research Instrument Inc, a home designed and constructed STM, and a simple FIM as shown in a somewhat over simplified two-dimensional diagram in Fig. 1 . In this instrument, a tip can be installed into the FIM through a vacuum lock tip changing chamber. Field ion images can be seen from a direction normal to the view of the figure using a $45^{\circ}$ mirror. The whole FIM assembly can be raised or lowered, so that once the tip is processed and characterized in the field ion microscope mode, it can be transferred to the scanning tunneling microscope by using the same sample transfer system. A similar vacuum lock is used for transferring samples from outside to the STM. This sample changing mechanism is normal to the view of Fig. 1, and is not shown. A sample can be transferred from the STM sample holder to the LEED sample holder and back using the same transferring system. In the LEED sample holder, the sample position can be adjusted in three directions, and its orientation can also be adjusted in two orthogonal angles. Therefore the sample surface can be made normal to the electron beam direction, and different spots of the sample surface can also be examined in the LEED mode. The sample can be heat treated by electron bombardments with a heating coil behind the sample.

Details of our STM design is shown in Fig. 2. We try to build a geometrically highly symmetric STM so that the problem of a thermal drift can be minimized. Thus we use a cross shape PZT for the $x$ and $y$ scanning of the tip, and a cylindrical PZT for probing the sample in the $z$ direction. The tip is mounted on a cone shaped sapphire, or machinable

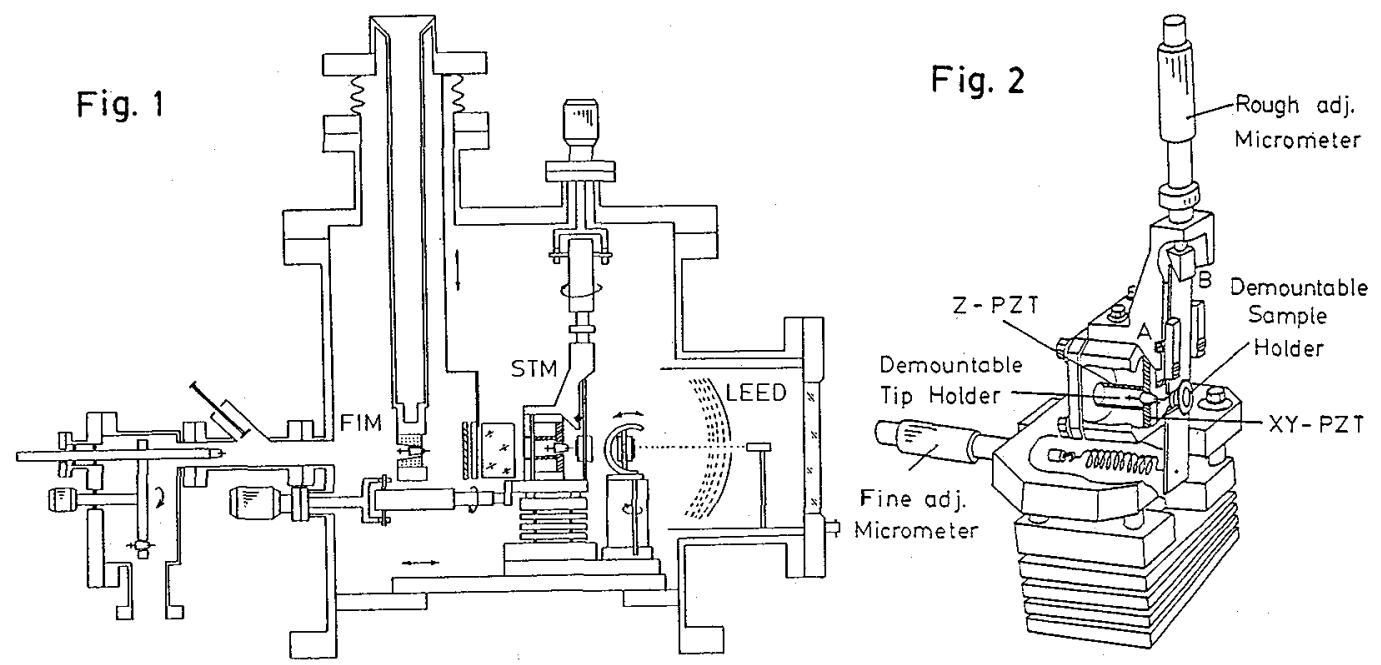


ceramic, which can be squeezed into the PZT. The sample can be slid into a stainless steel stripe which is pivoted at axis A. Rough adjustment of the sample-to-tip distance is done by adjusting the position of a wedge-shaped piece with a micrometer as shown in $B$. Fine adjustment is done by changing the tension of a spring coil with a micrometer. There is a ratio of about 1 : 200 of the spring constant of the coil and that of the stainless steel stripe. Our PZT has now a maximum scanning range of about $400 \AA$ in the $x$ and $y$ directions and about $200 \AA$ in the $z$ direction. With our design of the rough and fine adjustments, it is possible to adjust the tip-to-sample distance to less than $200 \AA$ by hand without smashing the tip into the sample. The STM sits on a stack of stainless steel plates separated by viton o-ring. At the present testing stage, the STM is placed on a commercial mechanical isolation table. The entire STM is covered with a heavy copper chamber. The inner wall of the chamber is lined with felt material to dampen sound waves which might echo within the chamber walls. With this design, we find the STM is mechanically stable to ordinary room vibrations and noises, such as walking steps, and bumping of the room doors etc.

\section{PRELIMINARY RESULT AND DISCUSSIONS}

Construction of the entire system is not yet completed. However, each individual system has been tested and is in good operating conditions. We present here some preliminary data obtained with the LEED system, and with the STM which is currently operated in air. For the LEED system, we test its performance by observing the (7×7) reconstruction of the $\mathrm{Si}$ (111) surface. A $\mathrm{Si}$ sample of about $5 \times 5 \mathrm{~mm}$ is cut from a (111) oriented sheet of thickness $\sim 0.5 \mathrm{~mm}$. It is polished carefully, and it is then prepared by wet chemical processes described by Ishizaka and Shiraki ${ }^{4}$ to remove surface impurities. This sample is then installed into the chamber, and is annealed by electron bombardments in vacuum in $10^{-10}$ Torr range. First, it is degased below $400^{\circ} \mathrm{C}$, and is then annealed to $850^{\circ} \mathrm{C}$ for 20 minutes. The temperature is measured with a Pt-Rh thermocouple which is held against the $\mathrm{Si}$ sample surface. A fast cooling rate will form the (1×1) structure, whereas a very slow cooling rate (less than $1{ }^{\circ} \mathrm{C} / \mathrm{s}$ ) will lead to the $(7 \times 7)$ reconstructed surface of the $S i$ (111) as shown in Fig. 3. We have also obtained LEED patterns of reconstructed $S i\{023\}$ surfaces, but details of this work will be presented elsewhere.

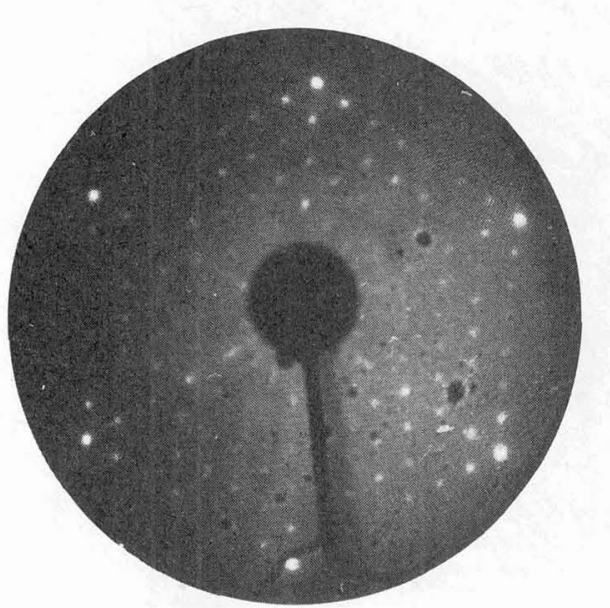

Fig. 3 
One of the greatest advantages of STM is that it can be operated in air or liquid. ${ }^{5}$ For the surfaces of non-oxidizing samples such as graphite and noble metals, the resolution and stability of STM are not affected by the operating environment of the STM provided that the tip is also stable in the same environment. For operating the STM in air, we therefore use Pt tips which are prepared from electrochemical polishing of a piece of $12 \mathrm{mil} \mathrm{Pt}$ wire. To obtain reproducible and stable STM images, it is most important to use tips of a large cone angle and a very short stem, so that mechanical vibrations can be reduced to the minimum. The following are selections of a large number of STM images we have obtained for various surfaces of different samples.

In Fig. 4 we show an atomically resolved STM image of the (111) surface of a graphite. Since we have not yet developed an image processing capability, no gray scale image of the same surface can be shown. If one examines this micrograph carefully, especially looking at a glazing angle, one can clearly see the hexagonal atomic arrangement. For the graphite (111) surface, occasionally we have also observed stepped structure. An example is shown in Fig. 5a, and the stepped structure is schematically shown in Fig. 5b. From the height of the ripples of the graphite atomic structure, we believe that the atomic step is monoatomic step in height.

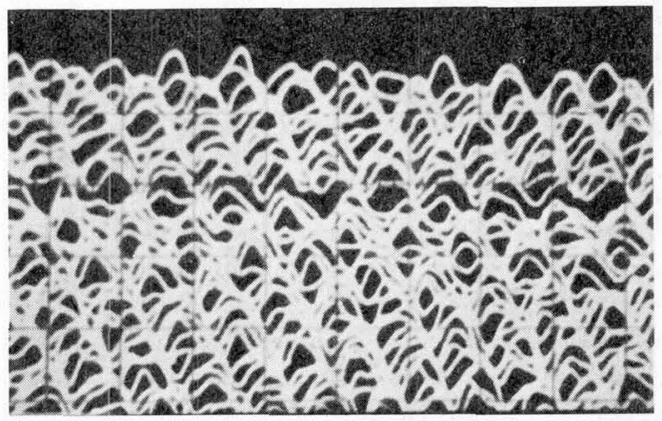

Fig. 4

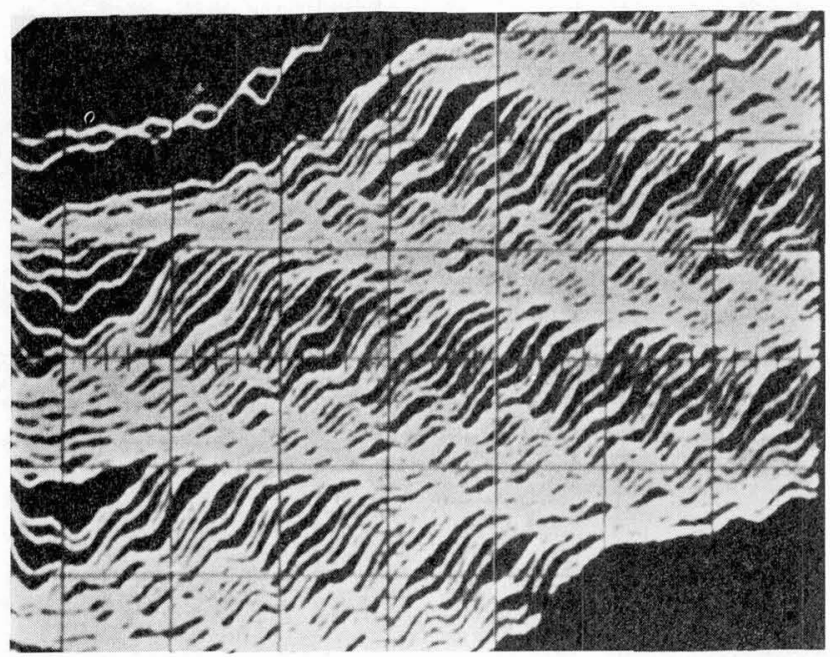

Fig. $5 a$.

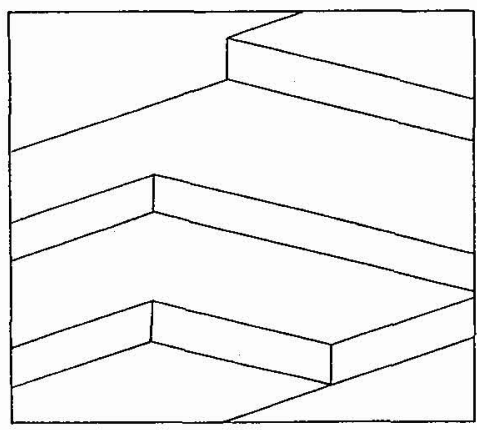

Fig. 5b. 
While atomically resolved images can only be obtained occasionally in air for graphite, images of lesser resolution of noble metal surfaces can be obtained routinely with the STM. In Fig. $6 a$ and $6 b$, two images of the same surface of a thin Pt sheet, 1 mil in thickness, are shown. The horizontal range is about $150 \AA$ and the vertical range is about $36 \AA$. The scanning frequency is $1 \mathrm{~Hz}$, and there are 128 scans although only about half of them are shown. These two images are taken about several minutes apart. If one examines the two images carefully, one finds that considerable structural changes have occurred. Structure changes are always found to occur within a few minutes for Pt and $\mathrm{Au}$ surfaces and thin films. These changes are in part due to the instability of the probing tip, and in part due to the dynamical behavior of the surfaces. Although $\mathrm{Pt}$ and Au surfaces are stable at $300 \mathrm{~K}$ in $\mathrm{UHV}^{6}{ }^{6}$ dynamical changes on atomic scale occur continuously in the atmosphere, possibly due to the effect of chemisorption. Atomic steps continue to change by dissociation, diffusion and association of plane edge atoms. We also find that when a new tip is used, the images always show greater details, but they are less stable. After some scanning, these images become more reproducible, but small structures are usually lost also. Yet the image structures continue to change with time.

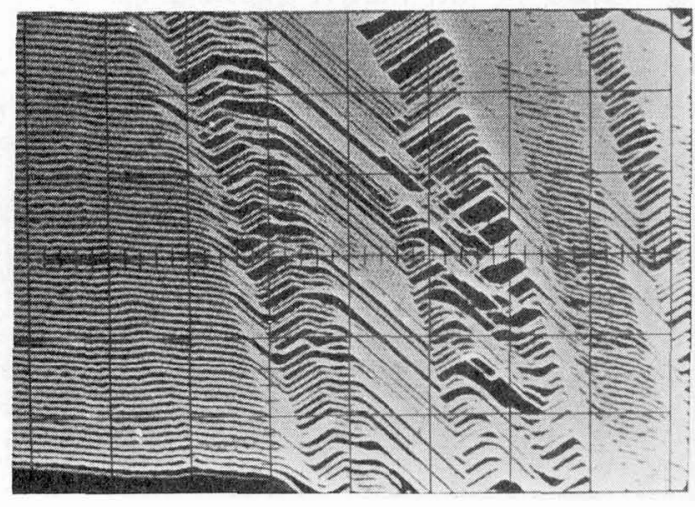

Fig. 6a.

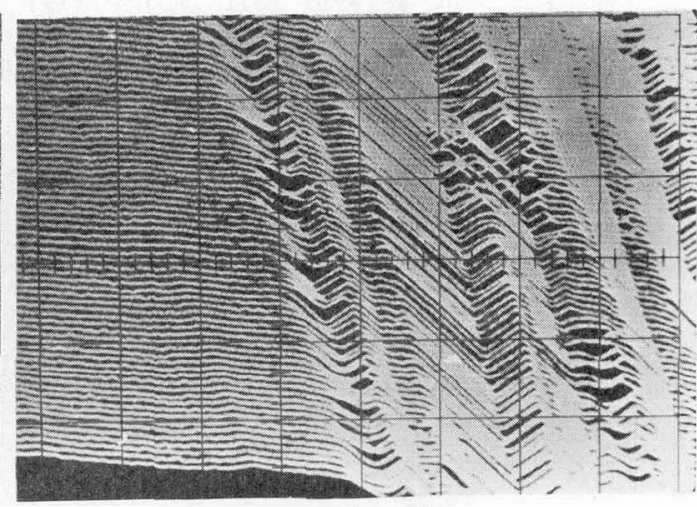

Fig. 6b.

In Fig. $7 a$ and $7 b$ we show images of two different kinds of gold surfaces. Fig. 7a is an image of a (111) surface of a Au melt. The surface is not completely flat, but has small step structures. The range of this picture is about $130 \times 33 \AA$. Fig. $7 \mathrm{~b}$ is an image of a gold film vapor deposited on the surface of a mica sheet. The film thickness is not known, but perhaps on the order of $1000 \AA$. The scan range is about $350 \times 100 \AA$.
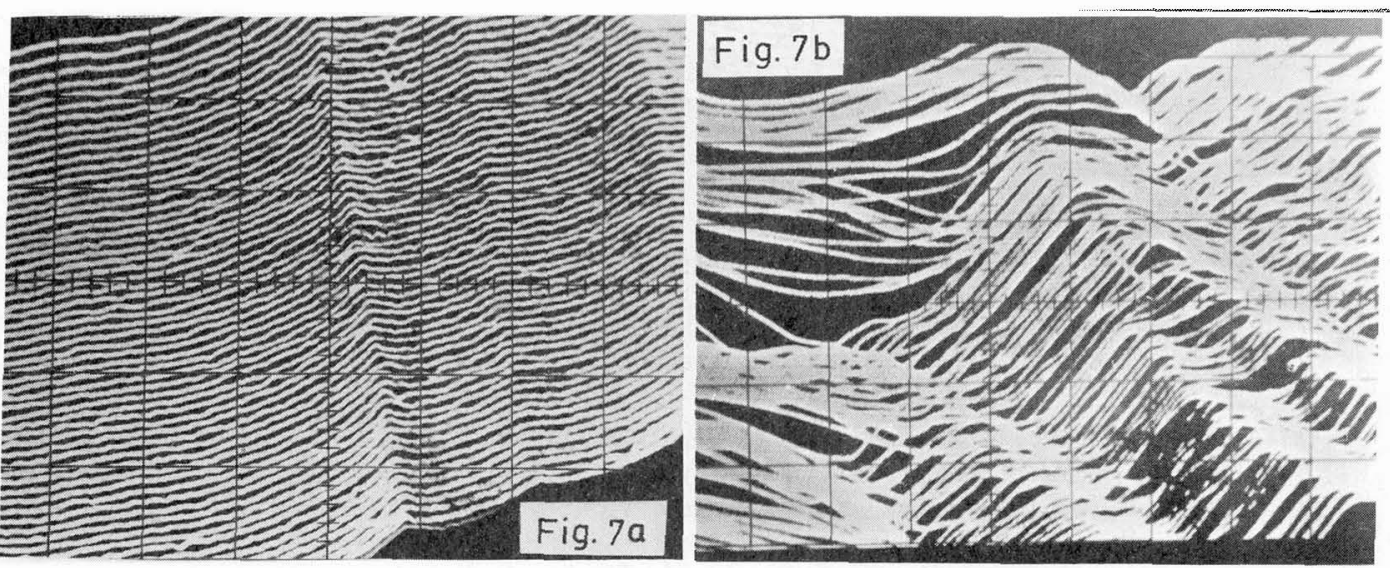
Fig. $8 a$ and $b$ show two images of rf sputter deposited Au thin films on Mo surface. The thin film should have columnar structures of a few hundreds $\AA .{ }^{7}$ As the scan range of our STM is a little to small, we usually see only a section of a column. The scan range is about $500 \times 140 \AA$ for Fig. 8a. In 8b, we combine two successive pictures, but with about five scan lines missing between the two. The total scan range is about $500 \times 200 \AA$. Fig. $8 \mathrm{c}$ show an image of rf sputter deposited Au particles on a carbon film. SEM images show that the particle size ranges from about $30 \AA$ to $70 \AA$. Although we can see Au particles of the correct size, the image is not very clear, perhaps limited by the shape of the tip used in this experiment.

This is a progress report. We are currently installing the STM into the vacuum chamber, and also building the FIM part and vacuum locks for the tip and sample replacement and exchanges. We hope to finish the system within a few months. At the moment, we are also developing a computer image processing capability. It is well known that pattern recognition is in general much easier with gray scale images.

We would like to thank many for their valuable advices. In particular, we would like to thank Y. Kuk of AT\&T Bell Laboratories, S. Chiang of IBM Almaden Laboratories, P. Hansma of U. C. Santa Barbara, and $O$. Nishikawa and M. Tomitori of Tokyo Institute of Technology: The rf sputtered Au thin film samples were prepared by $Y$. Liou and $R$. Messier of Penn State University. This project has been supported by NSF.

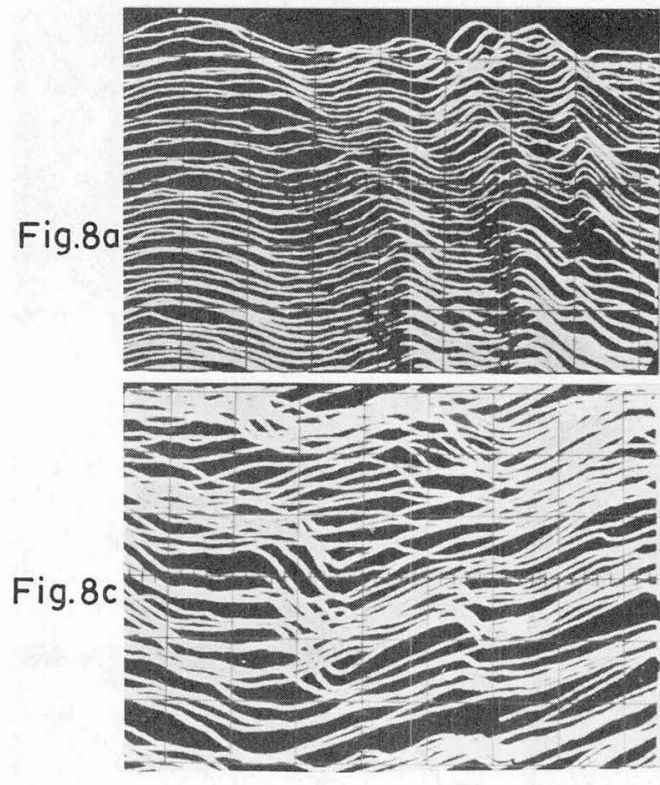

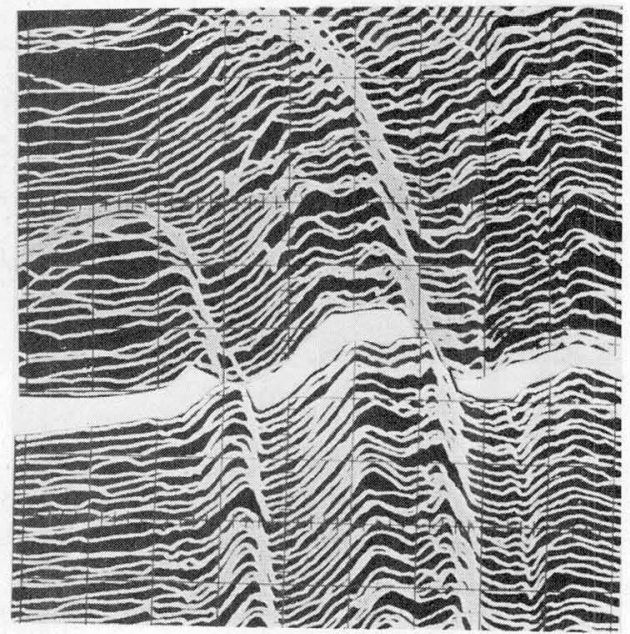

Fig. $8 b$

\section{REFERENCES}

1. See for example P. K. Hansma and J. Tersoff, J. App1. Phys., $\underline{61}$, R1 (1987).

2. Y. Kuk and P. J. Silverman, Appl. Phys. Lett., 48, 1597 (1986).

3. H. M. Liu, T. T. Tsong and Y. Liou, Phys. Rev. Lett., 58, 1535 (1987); T. T. Tsong, H.

M. Liu and D. L. Feng, Phys. Rev., B36, 4446 (1987).

4. A. Ishizawa and Y. Shiraki, Electrochem. Sci. Technol., 133, 666 (1986).

5. R. Sonnenfeld and P. K. Hansma, Scinece 232, 211 (1986).

6. For example see T. T. Tsong, Rep. Prog. Phys., 55, (1988).

7. S. V. Krishnaswamy, R. Messier, S. B. McLane, Y. S. Ng and T. T. Tsong, Thin solid Films 29, 21 (1981). 